\title{
Establishment of a prediction model of changing trends in cardiac hypertrophy disease based on microarray data screening
}

\author{
CAIYAN MA, YONGJUN YING, TIANJIE ZHANG, WEI ZHANG, \\ HUI PENG, XUFENG CHENG, LIN XU and HONG TONG
}

\author{
Cardiovascular Department, Tongde Hospital of Zhejiang Province, Hangzhou, Zhejiang 310012, P.R. China
}

Received December 29, 2014; Accepted January 15, 2016

DOI: 10.3892/etm.2016.3105

\begin{abstract}
The aim of the present study was to construct a mathematical model to predict the changing trends of cardiac hypertrophy at gene level. Microarray data were downloaded from Gene Expression Omnibus database (accession, GSE21600), which included 35 samples harvested from the heart of Wistar rats on postoperative days 1 (D1 group), 6 (D6 group) and 42 (D42 group) following aorta ligation and sham operated Wistar rats, respectively. Each group contained six samples, with the exception of the samples harvested from the aorta ligated group after 6 days, where $n=5$. Differentially expressed genes (DEGs) were identified using a Limma package in R. Hierarchical clustering analysis was performed on common DEGs in order to construct a linear equation between the D1 and D42 groups, using linear discriminant analysis. Subsequent verification was performed using receiver operating characteristic (ROC) curve and the measurement data at day 42. A total of 319 , 44 and 57 DEGs were detected in D1, D6 and D42 sample groups, respectively. AKIP1, ANKRD23, LTBP2, TGF- $\beta 2$ and TNFRSF $12 A$ were identified as common DEGs in all groups. The predicted linear equation between D1 and D42 group was calculated to be $y=1.526 x-186.671$. Assessment of the ROC curve demonstrated that the area under the curve was 0.831 , with a specificity and sensitivity of 0.8 . As compared with the predictive and measurement data at day 42 , the consistency of the two sets of data was $76.5 \%$. In conclusion, the present model may contribute to the early prediction of changing trends in cardiac hypertrophy disease at gene level.
\end{abstract}

Correspondence to: Mr. Caiyan Ma or Tianjie Zhang, Cardiovascular Department, Tongde Hospital of Zhejiang Province, 234 Gucui Road, Hangzhou, Zhejiang 310012, P.R. China

E-mail: caiyanmacym@163.com

E-mail: mcy-wj@163.com

Key words: cardiac hypertrophy, hierarchical clustering analysis, linear discriminant analysis, mathematical model, receiver operating characteristic curve

\section{Introduction}

Cardiac hypertrophy is associated with the thickening of the heart muscle (1) and the risk factors of cardiac hypertrophy include hypertension, obesity, muscular dystrophy, cardiomyopathy or heart failure (2). Furthermore, it has been demonstrated that genetic factors and signaling pathways may participate in the pathogenesis of cardiac hypertrophy, which may be associated with an enhanced risk of sudden cardiac death and cardiovascular mortality $(3,4)$. As the early symptoms of this disease are difficult to detect, it is crucial that novel molecular markers for the early therapy of cardiac hypertrophy are identified.

Molecular markers of cardiac hypertrophy have been identified (5). In particular, Kontaraki et al (6) identified GATA4, myocardin and $\beta$-myosin heavy chain as early cardiac marker genes. Furthermore, smooth muscle $\alpha$-actin has been demonstrated to be a molecular marker for pressure-overload hypertrophy (7). Using mouse models, Qing et al (8) have previously reported that $m i R-22$ serves a crucial function in the regulation of cardiac hypertrophy and cardiac remodeling. Fibroblast growth factor 21, which is an endocrine factor, has a protective role in cardiac cells (9). As an increasing number of molecular markers are identified, mathematical models can be constructed to predict the risk of cancer (10).

Various types of mathematical models have contributed to the prediction of diseases. Flux balance models of cellular metabolism have been used to analyze and predict transcriptional regulation under certain conditions, including catabolite repression and amino acid biosynthesis pathway repression (11). Furthermore, various genes and pathways associated with differentiation, including MAOA and ADH1B metabolic genes in human pulmonary type II cells (12) and nuclear factor-kappaB pathway in a mouse model of genitourinary inflammation (13), have been identified via mathematical cluster analysis using GENECLUSTER, which is a publicly available computer package that contributed to the establishment of an effective treatment for acute promyelocytic leukemia (14). According to a previous study conducted by Kondo and Miura (15), the reaction-diffusion model is effective in biological pattern formation. Thus, these previous studies suggest the mathematical modeling is a useful tool for the prediction of disease. 
Using microarray data downloaded from the Gene Expression Omnibus (GEO) database (accession, GSE21600), which included 35 heart samples harvested from a Wistar rat on postoperative days 1, 6 and 42 following aorta ligation and sham-operated Wistar rats, respectively. Hellman et al (16) demonstrated a correlation between hyaluronan concentration and specific gene expression levels using SPSS software. Analysis of the correlation matrix was performed according to the Principal components method (17), and orthogonal partial least squares-discrimination analysis was used to analyze the datasets of GSE21600, in which the previous clustering, including extracellular matrix and adhesion molecules were confirmed, and fatty acid metabolism, glucose metabolism, mitochondria and atherosclerosis were detected as the new clustering (18). However, these previous two studies failed to predict the changing trends of genes in this disease. Hence, the present study aimed to reanalyze the expression profiles of GSE21600 in order to construct a predictive model of cardiac hypertrophy using linear discriminant analysis (LDA) method. GSE21600 microarray data was used to identify differentially expressed genes (DEGs) using a Limma package in $\mathrm{R}$ (version. 3.26.5), which calculates linear models of microarray data. Common DEGs were used to construct a mathematical model in order to predict the expression levels of genes in the cardiac hypertrophy samples. The mathematical model was verified receiver operating characteristic (ROC) curve and the consistency of predictive and measurement data. The present study may be useful for the early prediction of changing trends in cardiac hypertrophy disease at the gene level.

\section{Materials and methods}

Data preprocessing and DEGs screening. GSE21600 microarray data were downloaded from the GEO database (http://www.ncbi.nlm.nih.gov/geo/) (16). GSE21600 included data from 35 heart samples harvested from 36 Wistar rats which were excised on postoperative days 1, 6 and 42 following aorta ligation and sham-operated groups, respectively. Each group contained six samples at each time point, with the exception of the samples harvested from the aorta ligated group at 6 days, where $n=5$. The microarray platform of GSE21600 was Illumina GPL6101 RatRef-12 expression bead chip (version 1.0; Illumina, Inc., San Diego, CA, USA).

Samples were divided into three groups: Day 1 (D1), day 6 (D6) and day 42 (D42). DEGs between the postoperative and sham-operated samples were identified in these three groups, respectively. Firstly, normalization of the microarray data was performed in the R language $(19,20)$, and DEGs were subsequently identified using a Limma package in $\mathrm{R}$ (21). False discovery rate (FDR) was used to adjust the $\mathrm{P}$-value, according to the method outlined by Benjamin and Hochberg (22). FDR $<0.05$ and $>1 \log _{2}$ fold change (FC) were chosen as the cut-off criteria.

Specific gene screening. In order to screen the specific expression levels of genes at each time point, DEGs were compared between the two groups. Subsequently, hierarchical clustering analysis (23) was performed on the common DEGs in the three groups.
Table I. Expression levels of five common differentially expressed genes the in aorta ligated operation group were calculated, as compared with the sham operated group.

\begin{tabular}{lccc}
\hline Gene & Day 1 & Day 6 & Day 42 \\
\hline AKIP1 & -1.24914 & -1.36699 & -1.80092 \\
ANKRD23 & -2.90253 & -3.69624 & -2.85077 \\
LTBP2 & -3.68846 & -4.20566 & -2.02513 \\
TGFB2 & -2.15313 & -2.11814 & -1.75841 \\
TNFRSF12A & -1.99987 & -2.08827 & -1.54923 \\
\hline
\end{tabular}

Sorting algorithm and construction of the mathematical model. Linear discriminant analysis (LDA) is a method that is commonly widely used in microarray classification to obtain discrimination function. LDA analysis can be performed when there are $\geq 2$ groups and each group contains $>2$ variables $(24,25)$. In this method, a linear equation based on the variations in the two groups is established: $Y=a+b_{11}+b_{22}+\ldots+b_{n} X_{n}$, where ' $a$ ' represents a constant and ' $b_{1} b_{2} \ldots$ and $b_{n}$ ' represents the regression coefficient. In the present study, the cardiac hypertrophy samples were defined as '1' and the control samples were defined as ' -1 '. Based on the dynamic expression changes of the common DEGs detected in the D1 group, the expression pattern in the D42 group was predicted via the calculated mathematical model constructed using the LDA method (26).

Verification of the mathematical model. Disease classification models are typically determined using multivariate regression analysis (27,28), ROC curve (29-32) or prospective validation (33). ROC curve was used in the present study in order to evaluate the discriminant effect of the mathematical model and directly observe the accuracy of the present analysis method. Indices, including specificity and sensitivity, were calculated in order to estimate the predictive ability of LDA, in addition to area under the curve (AUC) of the ROC curve, which was also calculated to estimate accuracy. In the present study, AUC was used to distinguish non-accuracy $(\mathrm{AUC} \leq 0.5)$, low accuracy $(0.5<\mathrm{AUC} \leq 0.7)$, moderate accuracy $(0.7<\mathrm{AUC} \leq 0.9)$ and high accuracy $(0.9<\mathrm{AUC}<1)$. Furthermore, by comparing the prediction data with the measurement data in the D42 samples, the consistency of two sets of data was evaluated.

\section{Results}

Identification, comparison and feature selection of DEGs. Normalization of the microarray data is presented in Fig. 1. DEGs were identified, and the genes with FDR $<0.05$ and $>1 \log _{2} \mathrm{FC}$ were considered as differentially expressed between the ligated samples and sham-operated samples. A total of 319, 44 and 57 DEGs were identified in the D1, D6 and D42 groups respectively.

A total of 23 DEGs were detected between the D1 and D6 groups, 14 DEGs were detected between the D1 and D42 groups, and five DEGs were identified between the D6 and D42 groups. Five common DEGs, including A kinase interacting protein $1(A K I P 1)$, ankyrin repeat domain 23 
Table II. Predicted data at day 42 using a linear equation of the gene expression levels of cardiac hypertrophy.

\begin{tabular}{|c|c|c|c|c|}
\hline Gene accession & State & Expression on day 1 & Expression on day 42 & Predicted on day 42 \\
\hline GSM539275 & 1 & 332.1987 & 337.3279 & 326.1898781 \\
\hline GSM539276 & 1 & 272.2375 & 126.1764 & 235.327208 \\
\hline GSM539277 & 1 & 485.7471 & 792.9784 & 558.8706386 \\
\hline GSM539278 & 1 & 778.9512 & 344.6311 & $1,003.179749$ \\
\hline GSM539279 & 1 & 320.8331 & 108.7458 & 308.9669279 \\
\hline GSM539280 & 1 & 716.3563 & 479.7876 & 908.3260809 \\
\hline GSM539281 & -1 & 85.13754 & 66.26252 & -48.1961695 \\
\hline GSM539282 & -1 & 71.55708 & 13.26508 & -68.775425 \\
\hline GSM539283 & -1 & 50.69723 & 41.25237 & -100.385561 \\
\hline GSM539284 & -1 & 23.54682 & 75.99313 & -141.528145 \\
\hline GSM539285 & -1 & 124.7012 & 29.73599 & 11.75692997 \\
\hline GSM539286 & -1 & 49.61586 & 52.55618 & -102.024223 \\
\hline GSM539275 & 1 & $4,201.869$ & $6,096.354$ & $6,190 \cdot 124821$ \\
\hline GSM539276 & 1 & $1,882.365$ & $5,415.158$ & $2,675.24642$ \\
\hline GSM539277 & 1 & $3,337.275$ & $9,621.91$ & $4,879.955589$ \\
\hline GSM539278 & 1 & $3,016.572$ & $4,261.265$ & $4,393.975807$ \\
\hline GSM539279 & 1 & $2,658.368$ & $3,865.638$ & $3,851.168593$ \\
\hline GSM539280 & 1 & $1,956.894$ & $8,021.108$ & $2,788.184519$ \\
\hline GSM539281 & -1 & $1,219.844$ & 959.4762 & $1,671.290077$ \\
\hline GSM539282 & -1 & $1,070.036$ & $1,546.261$ & $1,444.277361$ \\
\hline GSM539283 & -1 & $1,431.854$ & $1,145.456$ & $1,992.561078$ \\
\hline GSM539284 & -1 & $1,024.116$ & $3,023.837$ & $1,374.692133$ \\
\hline GSM539285 & -1 & 988.543 & $1,751.745$ & $1,320.786311$ \\
\hline GSM539286 & -1 & $1,213.691$ & $2,605.091$ & $1,661.966081$ \\
\hline GSM539275 & 1 & 880.5447 & 147.3087 & $1,157.130248$ \\
\hline GSM539276 & 1 & 126.5936 & 169.5375 & 14.62459301 \\
\hline GSM539277 & 1 & $1,011.612$ & 281.1071 & $1,355.744099$ \\
\hline GSM539278 & 1 & $1,073.774$ & 185.5347 & $1,449.941769$ \\
\hline GSM539279 & 1 & 340.023 & 62.10585 & 338.0464919 \\
\hline GSM539280 & 1 & 122.0065 & 237.4351 & 7.673495398 \\
\hline GSM539281 & -1 & 36.33411 & 32.24878 & -122.150826 \\
\hline GSM539282 & -1 & 50.67635 & 24.24548 & -100.417201 \\
\hline GSM539283 & -1 & 36.68185 & 45.16885 & -121.623876 \\
\hline GSM539284 & -1 & 30.85578 & 71.55927 & -130.452456 \\
\hline GSM539285 & -1 & 15.40947 & 32.20256 & -153.859142 \\
\hline GSM539286 & -1 & 34.06184 & 51.90232 & -125.594128 \\
\hline GSM539275 & 1 & $1,915.488$ & $1,621.039$ & $2,725.439616$ \\
\hline GSM539276 & 1 & 719.9728 & $1,732.95$ & 913.8063723 \\
\hline GSM539277 & 1 & $1,491.145$ & $1,375.875$ & $2,082.408155$ \\
\hline GSM539278 & 1 & $2,425.283$ & $3,341.205$ & $3,497.961428$ \\
\hline GSM539279 & 1 & $1,208.035$ & 885.0079 & $1,653.395218$ \\
\hline GSM539280 & 1 & $1,999.254$ & $1,564.762$ & $2,852.375074$ \\
\hline GSM539281 & -1 & 391.4185 & 495.3794 & 415.929062 \\
\hline GSM539282 & -1 & 355.6202 & 400.3427 & 361.6818301 \\
\hline GSM539283 & -1 & 437.2545 & 578.2272 & 485.3870006 \\
\hline GSM539284 & -1 & 215.4102 & 719.1659 & 149.2135176 \\
\hline GSM539285 & -1 & 464.529 & 402.5466 & 526.717626 \\
\hline GSM539286 & -1 & 483.1193 & 857.3302 & 554.8885815 \\
\hline GSM539275 & 1 & $1,776.678$ & 768.9708 & $2,515.092804$ \\
\hline GSM539276 & 1 & 998.7648 & 732.2133 & $1,336.275995$ \\
\hline GSM539277 & 1 & $2,373.809$ & $1,362.486$ & $3,419.959903$ \\
\hline GSM539278 & 1 & $3,322.548$ & $1,513.086$ & $4,857.638915$ \\
\hline
\end{tabular}


Table II. Continued.

\begin{tabular}{lcccc}
\hline Gene accession & State & Expression on day 1 & Expression on day 42 & Predicted on day 42 \\
\hline GSM539279 & 1 & 879.2261 & 513.2602 & $1,155.132097$ \\
GSM539280 & 1 & $1,201.621$ & $1,250.521$ & $1,643.675713$ \\
GSM539281 & -1 & 411.144 & 251.4373 & 445.8202516 \\
GSM539282 & -1 & 375.7809 & 208.7139 & 392.2325034 \\
GSM539283 & -1 & 406.536 & 168.1061 & 438.837483 \\
GSM539284 & -1 & 297.8341 & 399.4494 & 274.1152146 \\
GSM539285 & -1 & 322.7278 & 352.2844 & 311.8380763 \\
GSM539286 & -1 & 316.283 & 400.1669 & 302.0718985
\end{tabular}

1 , the aorta ligated operation group; -1 , the sham operated group.

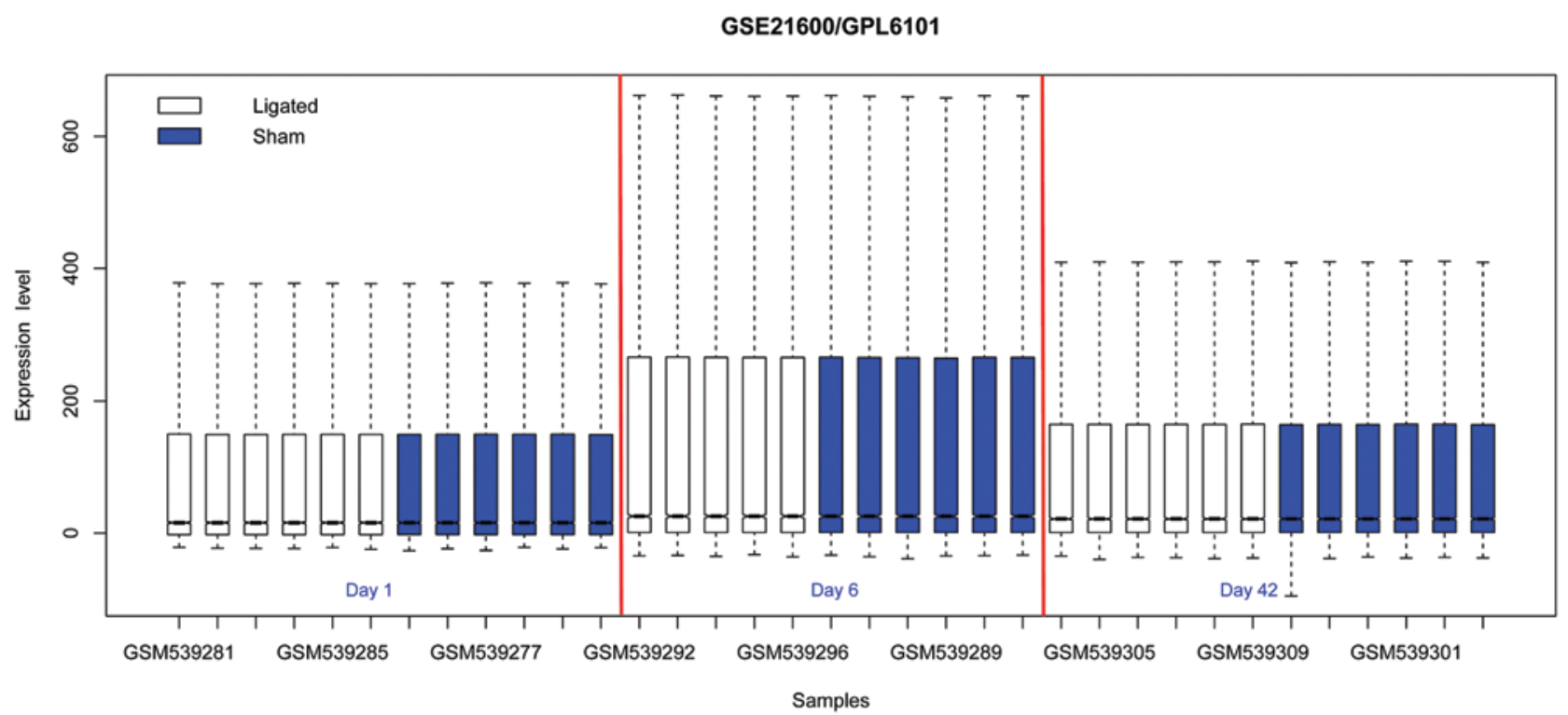

Figure 1. Microarray data normalization. Samples were divided into three groups: days 1, 6 and 42 . White, aorta ligated operation samples. Blue, sham operated samples.

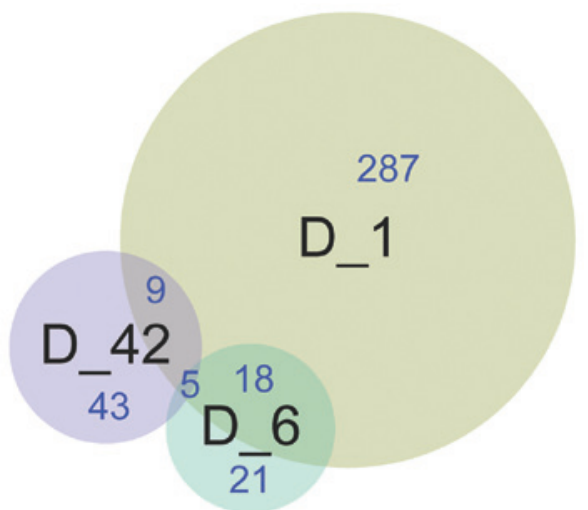

Figure 2. Identification of specific differentially expressed genes. Yellow, day 1 (D1) group; green, day 6 (D6) group; purple, day 42 (D42) group.

(ANKRD23), latent transforming growth factor beta binding protein (LTBP2), transforming growth factor $(T G F)-\beta 2$ and tumor necrosis factor receptor superfamily member $12 \mathrm{a}$
(TNFRSF12A), were identified among the three groups (Fig. 2).

Clustering analysis of the five common DEGs demonstrated that the sham operated and ligated samples were respectively clustered together; however, three ligated samples $(16.67 \% ; 3 / 18)$ were mixed into the operated group and two sham-operated samples $(11.76 \% ; 2 / 17)$ were mixed into the ligated group (Fig. 3). These five common DEGs were identified as downregulated genes (Table I).

Construction and verification of the mathematical model. Based on the expression levels and dynamic changes detected in the five common DEGs, a linear equation between the D1 and $\mathrm{D} 42$ groups was calculated as follows: $\mathrm{y}=1.526 \mathrm{x}-186.671$; where ' $y$ ' and ' $x$ ' represent the expression levels in the D42 and D1 groups, respectively.

Assessment of the ROC curve demonstrated that AUC was 0.831 , which indicated that the predictive accuracy was $83.1 \%$ and the specificity and sensitivity were 0.8 , respectively (Fig. 4A). By comparing the predictive and measurement data 


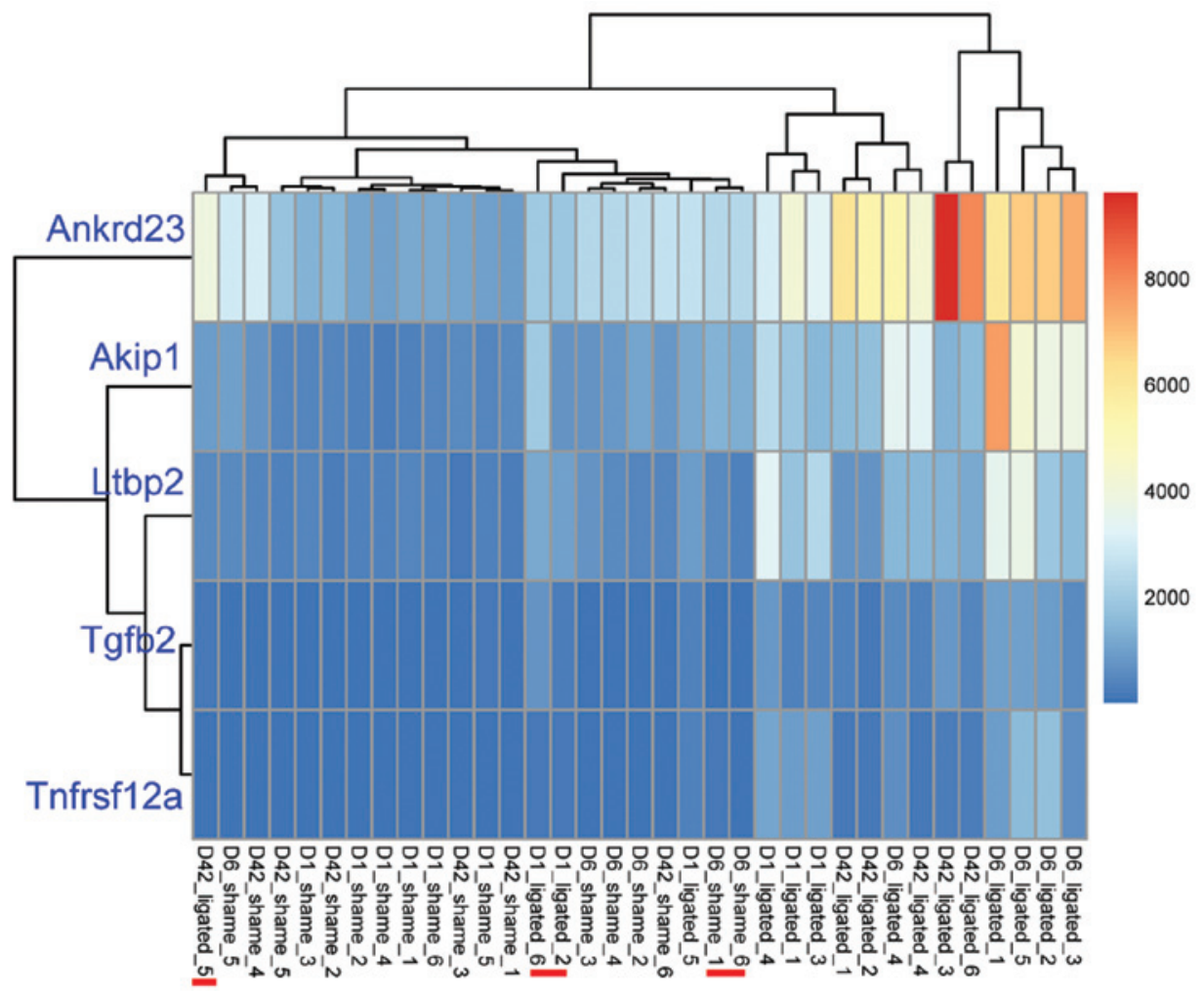

Figure 3. Hierarchical clustering analysis of five common differentially expressed genes in day 1 (D1), 6 (D6) and 42 (D42). Red labels represent the samples which were mixed into the false group.

A

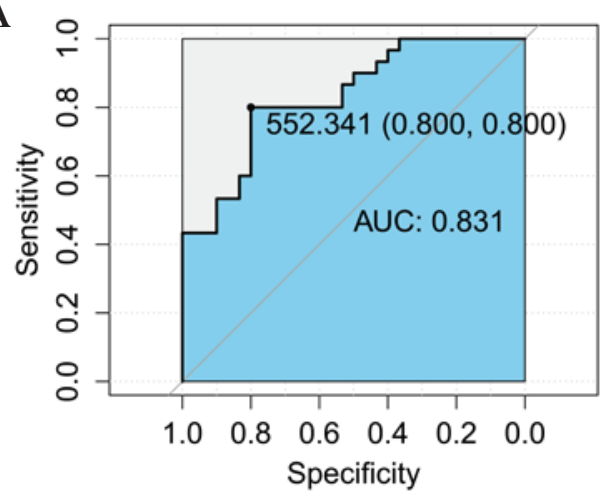

B

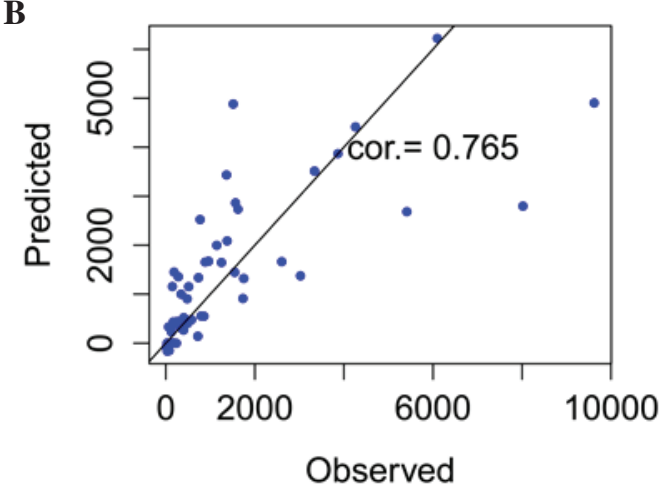

Figure 4. Verification of the prediction model. (A) The model was verified by receiver operating characteristic (ROC) curve (B), which was determined by the consistency of predictive and measurement data at day 42 . The area under curve (AUC) of ROC was used to assess the accuracy of data. AUC value $0.7<$ AUC $\leq 0.9$ implies moderate accuracy, whereas AUC value $0.9<\mathrm{AUC}<1$ implies high accuracy. Cor, correlation of predicted data and measurement data. at 42 days (Table II), the consistency of these two datasets was calculated to be $76.5 \%$ (Fig. 4B).

\section{Discussion}

In the present study, the expression profiles of sham operated and ligated heart samples harvested from a Wistar rat were analyzed and 319, 44 and 57 DEGs were subsequently identified in the D1, D6 and D42 groups, respectively. AKIP1, ANKRD23, $L T B P 2, T G F-\beta 2$ and TNFRSF12A were identified as common DEGs among the three groups, and their association with cardiac hypertrophy has previously been demonstrated (34-37). $A K I P I$ was identified as a key regulator of heart function via the cAMP-dependent protein kinase signaling pathway (38). During periods of the oxidant stress, the expression of AKIPI is capable of protecting cardiac myocytes from the ischemic injury via enhanced mitochondrial integrity (38). Furthermore, the expression of AKIP1 may also protect the heart via mitochondrial stress adaptation (39), and it has been demonstrated that mitochondrial DNA damage may contribute to the development of cardiac hypertrophy and heart failure (40). These results suggested that $A K I P 1$ may serve a crucial function in the development of cardiac hypertrophy via mitochondrial stress adaptation mechanisms. Hellman et al (16) have previously demonstrated that $L T B P 2$ and $T G F-\beta 2$ are associated with the development of cardiac hypertrophy. $L T B P 2$, which belongs to the fibrillin superfamily, regulates the release of $T G F-\beta 1$ (41,42). Previous studies have demonstrated that $T G F-\beta$, including $T G F-\beta 1, T G F-\beta 2$ and $T G F-\beta 3$, have an important role in the pathogenesis of cardiac hypertrophy by stimulating the proliferation of cardiomyocytes $(43,44)$. These 
results demonstrated that $L T B P 2$ and $T G F-\beta 2$ are associated with the regulation of cardiac hypertrophy. However, the role of ANKRD23 and TNFRSF12A in the development of cardiac hypertrophy is yet to be elucidated. As the results of the present study demonstrated that they were detected as common genes in the three groups, we hypothesize that AKIP1, ANKRD23, LTBP2, TGF- $\beta 2$ and TNFRSF12A may contribute to the development of cardiac hypertrophy.

Numerous mathematical techniques have been developed in order to analyze large datasets, and mathematical modeling is a useful and powerful tool for the analysis of gene expression patterns (14). LDA is a well-known multivariate technique that is used for dimension reduction and classification (45). A 3-gene model, TNFRSF8, BATF3 and TMOD1, which was obtained by LDA and leave-one-out cross-validation, was previously used to separate ALK (-) and anaplastic large-cell lymphoma from peripheral T-cell lymphoma, and the accuracy of the model was $\sim 97 \%$ (46). Furthermore, a class-prediction model of patients with Graft-vs-host disease was previously constructed using LDA, and the accuracy was 63-80\%, as estimated by reverse transcription-quantitative polymerase chain reaction (47). ROC, which directly displays the correlation of specificity and sensitivity can be used to assess the accuracy of diagnostic tests (48). In a previous study conducted by Barretina et al (49), Cancer Cell Line Encyclopedia, which is a predictive model, was cross-validated by specificity and sensitivity of the ROC curve and used to predict the drug response to gene expression, including topoisomerase inhibitors associated with Schlafen family member 11 . Similarly, a predictions model has previously been constructed for dementia using LDA and verified by ROC curve, and the accuracy of the model was $66 \%$; whereas the specificity and sensitivity were $73 \%$ and $64 \%$, respectively (50). In the present study, a prediction model of cardiac hypertrophy was constructed. The assessment of ROC curve demonstrated that the predictive accuracy of the model was $\sim 83.1 \%$ and the specificity and sensitivity were 0.8 , respectively. By comparing the predictive and measurement data at 42 days, the consistency of these two datasets was calculated to be $76.5 \%$. These results suggested that the present prediction model provides improved predictive ability, which may contribute to the early prediction of the changing trends in gene expression exhibited in patients with cardiac hypertrophy disease. However, to elevate the discrimination ability of the model, further studies with an increased number of samples and more suitable machine learning algorithm are required.

In the present study, 319, 44 and 57 DEGs were detected in D1, D6 and D42 groups, respectively. AKIP1, ANKRD23, LTBP 2, TGF- $\beta 2$ and TNFRSF $12 A$ were identified as common DEGs. A linear equation was calculated between the D1 and D42 groups, as follows: $y=1.526 x-186.671$. This linear equation, which acted as a prediction model of gene expression levels, may contribute to the early prediction of the changing trends in cardiac hypertrophy disease.

\section{Acknowledgements}

The authors of the present study would like to thank Fenghe Information Technology Co., Ltd (Shanghai, China) for in-depth editing and language assistance.

\section{References}

1. Heineke $\mathrm{J}$ and Molkentin JD: Regulation of cardiac hypertrophy by intracellular signalling pathways. Nat Rev Mol Cell Biol 7: 589-600, 2006

2. Hubert HB, Feinleib M, McNamara PM and Castelli WP: Obesity as an independent risk factor for cardiovascular disease: A 26-year follow-up of participants in the Framingham Heart Study. Circulation 67: 968-977, 1983.

3. Wang AY, Wang M, Woo J, Lam CW, Lui SF, Li PK and Sanderson JE: Inflammation, residual kidney function and cardiac hypertrophy are interrelated and combine adversely to enhance mortality and cardiovascular death risk of peritoneal dialysis patients. J Am Soc Nephrol 15: 2186-2194, 2004.

4. Dunn FG, Burns JM and Hornung RS: Left ventricular hypertrophy in hypertension. Am Heart J 122: 312-315, 1991.

5. Osio A, Tan L, Chen SN, Lombardi R, Nagueh SF, Shete S, Roberts R, Willerson JT and Marian AJ: Myozenin 2 is a novel gene for human hypertrophic cardiomyopathy. Circ Res 100: 766-768, 2007.

6. Kontaraki JE, Parthenakis FI, Patrianakos AP, Karalis IK and Vardas PE: Altered expression of early cardiac marker genes in circulating cells of patients with hypertrophic cardiomyopathy. Cardiovasc Pathol 16: 329-335, 2007.

7. Black FM, Packer SE, Parker TG, Michael LH, Roberts R, Schwartz RJ and Schneider MD: The vascular smooth muscle alpha-actin gene is reactivated during cardiac hypertrophy provoked by load. J Clin Invest 88: 1581-1588, 1991.

8. Qing YF, Zhou JG, Zhang QB, Wang DS, Li M, Yang QB, Huang CP, Yin L, Pan SY, Xie WG, et al: Association of TLR4 Gene rs2149356 polymorphism with primary gouty arthritis in a case-control study. PLoS One 8: e64845, 2013.

9. Planavila A, Redondo I, Hondares E, Vinciguerra M, Munts C, Iglesias R, Gabrielli LA, Sitges M, Giralt M, van Bilsen M and Villarroya F: Fibroblast growth factor 21 protects against cardiac hypertrophy in mice. Nat Commun 4: 2019, 2013.

10. Grimwade D, Walker H, Oliver F, Wheatley K, Harrison C, Harrison G, Rees J, Hann I, Stevens R, Burnett A and Goldstone A: The importance of diagnostic cytogenetics on outcome in AML: Analysis of 1,612 patients entered into the MRC AML 10 trial. The medical research council adult and children's leukaemia working parties. Blood 92: 2322-2333, 1998.

11. Covert MW, Schilling CH and Palsson B: Regulation of gene expression in flux balance models of metabolism. J Theor Biol 213: 73-88, 2001.

12. Wade KC, Guttentag SH, Gonzales LW, Maschhoff KL, Gonzales J, Kolla V, Singhal S and Ballard PL: Gene induction during differentiation of human pulmonary type II cells in vitro. Am J Respir Cell Mol Biol 34: 727-737, 2006.

13. Saban MR, Hellmich H, Nguyen NB, Winston J, Hammond TG and Saban R: Time course of LPS-induced gene expression in a mouse model of genitourinary inflammation. Physiol Genomics 5: 147-160, 2001.

14. Tamayo P, Slonim D, Mesirov J, Zhu Q, Kitareewan S, Dmitrovsky E, Lander ES and Golub TR: Interpreting patterns of gene expression with self-organizing maps: Methods and application to hematopoietic differentiation. Proc Natl Acad Sci USA 96: 2907-2912, 1999.

15. Kondo S and Miura T: Reaction-diffusion model as a framework for understanding biological pattern formation. Science 329: 1616-1620, 2010.

16. Hellman U, Mörner S, Engström-Laurent A, Samuel JL and Waldenström A: Temporal correlation between transcriptional changes and increased synthesis of hyaluronan in experimental cardiac hypertrophy. Genomics 96: 73-81, 2010.

17. Revell LJ. Size-correction and principal components for interspecific comparative studies. Evolution 12: 3258-3268, 2009.

18. Gennebäck N, Malm L, Hellman U, Waldenström A and Mörner S: Using OPLS-DA to find new hypotheses in vast amounts of gene expression data-Studying the progression of cardiac hypertrophy in the heart of aorta ligated rat. Gene 522: 27-36, 2013.

19. Troyanskaya O, Cantor M, Sherlock G, Brown P, Hastie T, Tibshirani R, Botstein D and Altman RB: Missing value estimation methods for DNA microarrays. Bioinformatics 17: 520-525, 2001.

20. Fujita A, Sato JR, Rodrigues Lde O, Ferreira CE and Sogayar MC: Evaluating different methods of microarray data normalization. BMC Bioinformatics 7: 469, 2006. 
21. Smyth GK: Limma: Linear models for microarray data. In: Bioinformatics and computational biology solutions using $\mathrm{R}$ and Bioconductor. Gentleman R, Carey V, Huber W, Irizarry R and Dudiot S (eds). Springer-Verlag London Ltd., London, pp397-420, 2005.

22. Benjamini Y and Hochberg Y: Controlling the false discovery rate: A practical and powerful approach to multiple testing. J R Statist Soc B 57: 289-300, 1995.

23. Eisen MB, Spellman PT, Brown PO and Botstein D: Cluster analysis and display of genome-wide expression patterns. Proc Natl Acad Sci USA 95: 14863-14868, 1998.

24. Liang J and Du R: Model-based fault detection and diagnosis of HVAC systems using support vector machine method. Int J Refrig 30: 1104-1114, 2007.

25. Polat $K$ and Güneş S: Breast cancer diagnosis using least square support vector machine. Digit Signal Process 17: 694-701, 2007.

26. Chen LF, Liao HYM, Ko MT, Lin JC and Yu GJ: A new LDA-based face recognition system which can solve the small sample size problem. Pattern Recognition 33: 1713-1726, 2000

27. Jiang H, Deng Y, Chen HS, Tao L, Sha Q, Chen J, Tsai CJ and Zhang S: Joint analysis of two microarray gene-expression data sets to select lung adenocarcinoma marker genes. BMC Bioinformatics 5: 81, 2004.

28. Imai K. Multivariate regression analysis for the item count technique. J Amer Statist Assoc 106: 407-416, 2011.

29. Zhou L, Cheng L, Tao L, Jia X, Lu Y and Liao P: Detection of hypopharyngeal squamous cell carcinoma using serum proteomics. Acta Otolaryngol 126: 853-860, 2006.

30. Navaglia F, Fogar P, Basso D, Greco E, Padoan A, Tonidandel L, Fadi E, Zambon CF, Bozzato D, Moz S, et al: Pancreatic cancer biomarkers discovery by surface-enhanced laser desorption and ionization time-of-flight mass spectrometry. Clin Chem Lab Med 47: 713-723, 2009.

31. Hewett R and Kijsanayothin P: Tumor classification ranking from microarray data. BMC Genomics 9 (Suppl 2): S21, 2008.

32. Roepman P, Schuurman A, Delahaye LJ, Witteveen AT, Floore AN and Glas AM: A gene expression profile for detection of sufficient tumour cells in breast tumour tissue: Microarray diagnosis eligibility. BMC Med Genomics 2: 52, 2009.

33. Ye QH, Qin LX, Forgues M, He P, Kim JW, Peng AC, Simon R, Li Y, Robles AI, Chen Y, et al: Predicting hepatitis $\mathrm{B}$ virus-positive metastatic hepatocellular carcinomas using gene expression profiling and supervised machine learning. Nat Med 9: 416-423, 2003.

34. Yu H, Tigchelaar W, Lu B, van Gilst WH, de Boer RA, Westenbrink BD and Silljé HH: AKIP1, a cardiac hypertrophy induced protein that stimulates cardiomyocyte growth via the Akt pathway. Int J Mol Sci 14: 21378-21393, 2013.

35. Bang ML, Gu Y, Dalton ND, Peterson KL, Chien KR and Chen J: The muscle ankyrin repeat proteins CARP, Ankrd2, and DARP are not essential for normal cardiac development and function at basal conditions and in response to pressure overload. PloS One 9: e93638, 2014.

36. Kuba K, Zhang L, Imai Y, Arab S, Chen M, Maekawa Y, Leschnik M, Leibbrandt A, Markovic M, Schwaighofer J, et al: Impaired heart contractility in Apelin gene-deficient mice associated with aging and pressure overload. Circ Res 101: e32-e42, 2007.
37. Dobaczewski M, Chen W and Frangogiannis NG: Transforming growth factor (TGF) $-\beta$ signaling in cardiac remodeling. J Mol Cell Cardiol 51: 600-606, 2011.

38. Sastri M, Haushalter KJ, Panneerselvam M, Chang P, Fridolfsson H, Finley JC, Ng D, Schilling JM, Miyanohara A, Day ME, et al: A kinase interacting protein (AKIP1) is a key regulator of cardiac stress. Proc Natl Acad Sci USA 110: E387-E396, 2013.

39. Yu H, Tigchelaar W, Koonen DP, Patel HH, de Boer RA, van Gilst WH, Westenbrink BD and Silljé HH: AKIP1 expression modulates mitochondrial function in rat neonatal cardiomyocytes. PLoS One 8: e80815, 2013.

40. Dai DF, Johnson SC, Villarin JJ, Chin MT, Nieves-Cintrón M, Chen T, Marcinek DJ, Dorn GW II, Kang YJ, Prolla TA, et al: Mitochondrial oxidative stress mediates angiotensin II-induced cardiac hypertrophy and Galphaq overexpression-induced heart failure. Circ Res 108: 837-846, 2011.

41. Sinha S, Heagerty AM, Shuttleworth CA and Kielty CM: Expression of latent TGF-beta binding proteins and association with TGF-betal and fibrillin-1 following arterial injury. Cardiovasc Res 53: 971-983, 2002.

42. Sterner-Kock A, Thorey IS, Koli K, Wempe F, Otte J, Bangsow T, Kuhlmeier K, Kirchner T, Jin S, Keski-Oja J and von Melchner H: Disruption of the gene encoding the latent transforming growth factor-beta binding protein 4 (LTBP-4) causes abnormal lung development, cardiomyopathy, and colorectal cancer. Genes Dev 16: 2264-2273, 2002

43. Bujak M and Frangogiannis NG: The role of TGF-beta signaling in myocardial infarction and cardiac remodeling. Cardiovasc Res 74: 184-195, 2007.

44. Dobaczewski M, Chen W and Frangogiannis NG: Transforming growth factor (TGF)- $\beta$ signaling in cardiac remodeling. J Mol Cell Cardiol 51: 600-606, 2011.

45. Roth V and Steinhage V: Nonlinear discriminant analysis using kernel functions. In: Advances in Neural Information Processing Systems. Vol 12. Solla SA, Leen TK and Müller KR (eds). MIT Press, Cambridge, MA, pp568-574, 2000.

46. Agnelli L, Mereu E, Pellegrino E, Limongi T, Kwee I, Bergaggio E, Ponzoni M, Zamò A, Iqbal J, Piccaluga PP, et al; European T-Cell Lymphoma Study Group: Identification of a 3-gene model as a powerful diagnostic tool for the recognition of ALK-negative anaplastic large-cell lymphoma. Blood 120: 1274-1281, 2012.

47. Baron C, Somogyi R, Greller LD, Rineau V, Wilkinson P, Cho CR, Cameron MJ, Kelvin DJ, Chagnon P, Roy DC, et al: Prediction of graft-versus-host disease in humans by donor gene-expression profiling. PLoS Med 4: e23, 2007.

48. Beck JR and Shultz EK: The use of relative operating characteristic (ROC) curves in test performance evaluation. Arch Pathol Lab Med 110: 13-20, 1986.

49. Barretina J, Caponigro G, Stransky N, Venkatesan K, Margolin AA, Kim S, Wilson CJ, Lehár J, Kryukov GV, Sonkin D, et al: The Cancer Cell Line Encyclopedia enables predictive modelling of anticancer drug sensitivity. Nature 483: 603-607, 2012.

50. Maroco J, Silva D, Rodrigues A, Guerreiro M, Santana I and de Mendonça A: Data mining methods in the prediction of Dementia: A real-data comparison of the accuracy, sensitivity and specificity of linear discriminant analysis, logistic regression, neural networks, support vector machines, classification trees and random forests. BMC Res Notes 4: 299, 2011. 